\title{
OPTIMIZATION OF ALKALI ACTIVATION OF GROUND GRANULATED SLAG WITH MINING TAILS
}

\author{
Pablo Santizo Matheu ${ }^{1}$, Ashley Waldron², Benjamin Varela ${ }^{3}$ \\ ${ }^{1}$ Department of Mechanical Engineering, Rochester Institute of Technology, Rochester, NY \\ ${ }^{2}$ Department of Mechanical Engineering, Rochester Institute of Technology, Rochester, $N Y$ \\ ${ }^{3}$ Department of Mechanical Engineering, Rochester Institute of Technology, Rochester, $N Y$
}

\begin{abstract}
Previous studies have shown that the reinforcement of alkali activated ground granulated blast furnace slag (GGBFS) with Wollastonite micro-fibers enhances the compressive strength and thermal stability of the composite.

Compressive strength of alkali activated slag with $10 \%$ of Wollastonite per mass reached a 7 day compressive strength of 55.15 $\mathrm{MPa}(8000 \mathrm{psi})$. However, the estimated cost of this formulation is six times greater than similar concretes based on ordinary Portland cement. Different aggregates were tested to reduce the cost of this formulation. It was found that when mine tailings were added, the 7 day compressive strength reached $41.36 \mathrm{MPa}(6000 \mathrm{psi})$ ), the setting time doubled and the cost was reduced by 2/3. These results are promising for the development of a cost effective formulation.

Based on these results, a two factorial design with a three level design of experiments was conducted to explore the joint effect of Wollastonite and mine tailings on alkali activated GGBFS. In order to find the significant factors, the compressive strength would act as the response variable. The setting time and cost of each combination is also considered to find the optimal combination resulting from the experiment.
\end{abstract}

Keywords: Wollastonite micro-fibers, ground granulated blast furnace slag, alkali-activation, reinforcement, mine tailings

\section{INTRODUCTION}

From a sustainable perspective, the production of Portland cement is harmful to the environment due to high energy consumption and $\mathrm{CO}_{2}$ emission release. However, it is necessary for the development and growth of any country. In 2012 alone, the United States of America produced approximately 71 million tons of Portland cement. This country is the third largest producer of this material after China and India [1]. Portland cement has been used since 1824. However, it is now under scrutiny because of the adverse environmental impact. In order to produce one ton of regular Portland cement, one ton of $\mathrm{CO}_{2}$ is emitted to the atmosphere [2]. Together with $\mathrm{CO}_{2}$, other greenhouse gasses like sulfur dioxides, nitrogen dioxides, carbon monoxide and particulate matter from flue gas are emitted during the production process. This product also represents a threat to the environment due to required virgin raw materials.

Cement production is anenergy intensive process; it needs a continuous reliable source of energy. The production of clinker is the process that demands the most amount of energy and represents approximately 60 percent of the $\mathrm{CO}_{2}$ emissions created by cement [3].

Due to these known negative effects, there have been several researchers looking for a viable replacement for Portland cement, with similar or better mechanical properties and a minimized environmental impact. A current example of research in this field include geopolymers [4] which represent a great option for the future and opens several doors for research. Fundamental research of alkali activated materials has received international interest since the 1990's [5]

GGBFS represents an opportunity to eliminate the need for the high energy consumption,reduction of $\mathrm{CO}_{2}$ emissions and the amount of virgin raw materials. The capacity of GGBFS to produce a cementitious material under alkali activation has been known since the 1940's [6]. However, in the last decades there has been a growing interest in the development of this technology for different applications $[7,8]$.The objective of this work mainly focused on the application of this technology to by-product materials available in Western New York, with the goal of developing a cost effective cementitious material.

In previous research, an optimal molar ratio formulation for a potassium based activating solution was found. The average of the compressive strength given by this formulation is approximately 55.15 $\mathrm{MPa}(8,000 \mathrm{psi})$ [9]. A cost analysis of this formulation was done and the price per ton of the alkali-activated slag versus Portland cement was about 6.4 times more expensive, mainly because of the cost of the alkali activating solution.Only special applications can justify the high cost for this compressive strength. The 
main objective of this work was to create a more economically viable formulation by using a less concentrated alkali solution and using mining tails, as as aggregate. The mining tails used are a byproduct of the processing of wollastonite at NYCO Minerals in Willsboro $\mathrm{NY}$ and they were used as received.

A logical reason for why Portland cement is continuing to be the most common type of cement is the abundant and geologically widespread availability of the raw materials needed. The problem is that as all the virgin raw materials, even though there seems to be a great quantity, will eventually be limited. The by-products, GGBFS and mining tails, used in this experiment were provided by companies located in New York State. By getting the materialsfrom a close location, the cost and damage caused by the logistics and transportation are dramatically reduced. The easy accessibility of these aggregates represents a great opportunity for the North Eastern part of the United States of America.

\section{EXPERIMENTAL}

\subsection{Materials Properties and Preparation}

The GGBFS (St. Mary's Cement, Ontario, Canada) used in these experiments was provided by Manitou Concrete, Rochester, NY. The Blaine fineness of this GGBFS is 660 $\mathrm{m}^{2} / \mathrm{kg}$ and its primary chemical composition is provided in Table 1

Table1: Chemical composition of GGBFS in mass percentage of main oxides as provided by the supplier.

\begin{tabular}{|l|l|}
\hline Oxide & \% \\
\hline $\mathrm{CaO}$ & 38.30 \\
\hline $\mathrm{SiO}_{2}$ & 37.00 \\
\hline $\mathrm{Al}_{2} \mathrm{O}_{3}$ & 8.00 \\
\hline $\mathrm{MgO}$ & 10.50 \\
\hline $\mathrm{K}_{2} \mathrm{O}$ & 0.43 \\
\hline $\mathrm{Na}_{2} \mathrm{O}$ & 0.25 \\
\hline $\mathrm{SO}_{3}$ & 1.70 \\
\hline
\end{tabular}

The mining tails used for this work were provided by NYCO Minerals located in Willsboro, NY. This by-product is obtained during the purification of the Wollastonite ore. The chemical composition is presented in Table2.

Table 2: Chemical composition of Mining Tails in mass percentage of main oxides as provided by the supplier

\begin{tabular}{|l|l|}
\hline Oxide & \% \\
\hline $\mathrm{SiO}_{2}$ & 53.40 \\
\hline $\mathrm{TiO}_{2}$ & 0.14 \\
\hline $\mathrm{Al}_{2} \mathrm{O}_{3}$ & 4.22 \\
\hline $\mathrm{Fe}_{2} \mathrm{O}_{3}$ & 10.90 \\
\hline $\mathrm{MnO}$ & 0.19 \\
\hline $\mathrm{MgO}$ & 2.38 \\
\hline $\mathrm{CaO}$ & 33.90 \\
\hline $\mathrm{Na}_{2} \mathrm{O}$ & 0.10 \\
\hline $\mathrm{K}_{2} \mathrm{O}$ & 0.05 \\
\hline $\mathrm{P}_{2} \mathrm{O}_{5}$ & 0.19 \\
\hline
\end{tabular}

\begin{tabular}{|l|l|} 
LOI & 0.21 \\
\hline
\end{tabular}

In a previous study, a potassium based, alkali solution with molar ratios of $\mathrm{SiO}_{2} / \mathrm{K}_{2} \mathrm{O}=1$ and $\mathrm{H}_{2} \mathrm{O} / \mathrm{K}_{2} \mathrm{O}=10$ were found to be optimal for compressive strength and setting time. However, the cost of this activating solution was found to be approximately US $\$ 923.58$ per metric ton. In this study, an alkali solution with molar ratios of $\mathrm{SiO}_{2} / \mathrm{K}_{2} \mathrm{O}=1$ and $\mathrm{H}_{2} \mathrm{O} / \mathrm{K}_{2} \mathrm{O}=50$ was used in order to reduce the overall cost to approximately \$291.89 per metric ton. This solution was prepared by dissolving amorphous silica, Aerosil 300 produced by EvonicIndustires, in a $45 \% \mathrm{KOH}$ solution produced by Brainerd Chemical Company. Distilled water was using in all experiments. Once the appropriate amounts were mixed, the solution was left to rest for 24 hours before being used.

In order to keep consistency among all samples, the following procedure was used: Thoroughly mixed all dry components, add the activating solution and mixed all together for 3 minutes in a Hobart mixer, in order to create a homogenous paste. This paste was then cast into cylindrical molds. While casting the paste; the molds were placed on a vibrating surface to minimize the formation of air bubbles. The samples were then left to dry for 1 hour at room temperature and then put in a convection oven at $45{ }^{\circ} \mathrm{C}$ to cure for 12 hours.

Compressive strength of the cylinders, with diameter of 31 $\mathrm{mm}$ by $38 \mathrm{~mm}$ long, at one, seven and fifteen days using a Tinius Olsen universal testing machine.

\subsection{Characterization}

Figures 1a and $1 \mathrm{~b}$ present optical micrographs (Olympus BX60M) of samples without wollastonite. These micrographs revealed that mining tails particles have sharp edges and a broad distribution ranging from 600 to $100 \mu \mathrm{m}$. Some particles of wollastonite were also detected as well as large pores in the range of 100 to $30 \mu \mathrm{m}$.

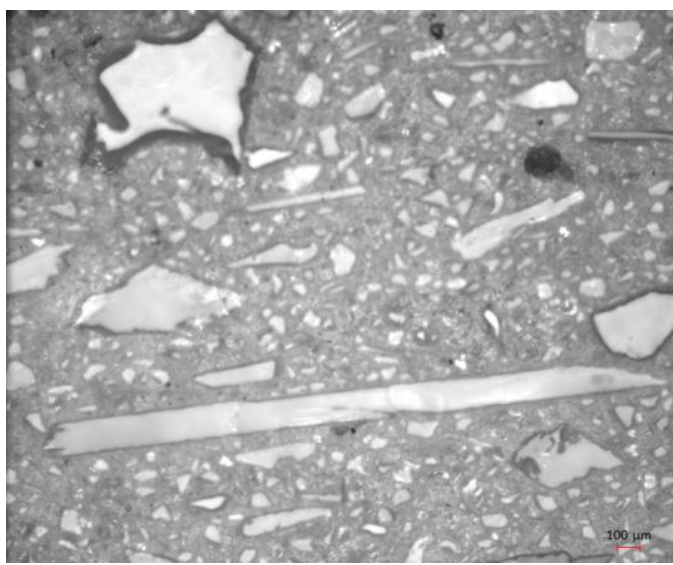

Fig 1a Optical micrographs of alkali activated slag without Wollastonite at $200 \mathrm{X}$. 


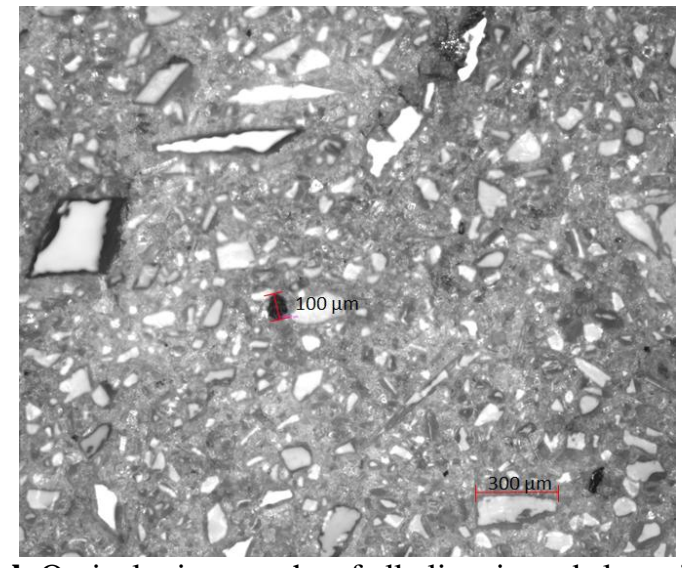

Fig 1 b Optical micrographs of alkali activated slag without Wollastonite at 200X.

Scanning electron microscopy (Amray 1830) of the alkali activated slagrevealed the formation of a primarily irregular formation with coagulates of a secondary phase (Figure 2a). Further analysis of thesephases using EDX revealed that the coagulated phase is composed of $\mathrm{K}$ and $\mathrm{Si}$ (Figure 2b) while the other phase is composed of $\mathrm{Ca}$ and $\mathrm{Si}$, suggesting the formation of C-S-H (Figure 2c and 2d)

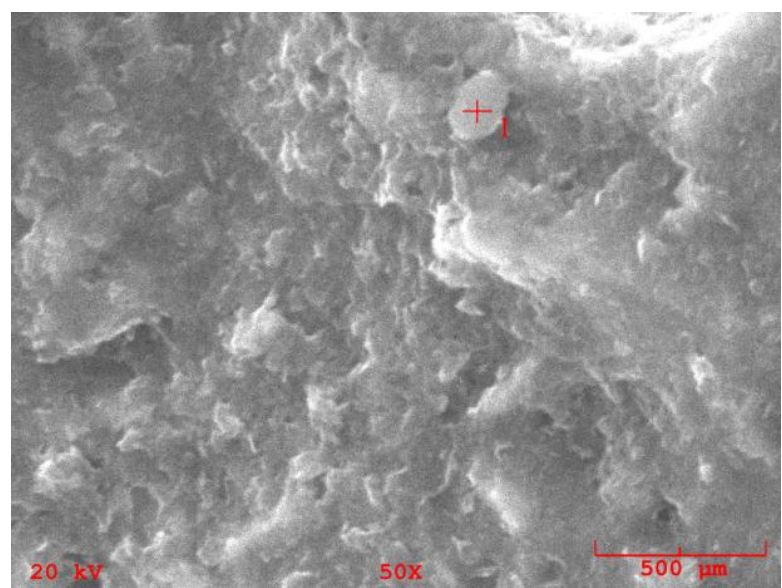

Fig 2a SEM micrographs analysis for the formations observed in alkali activated slag.

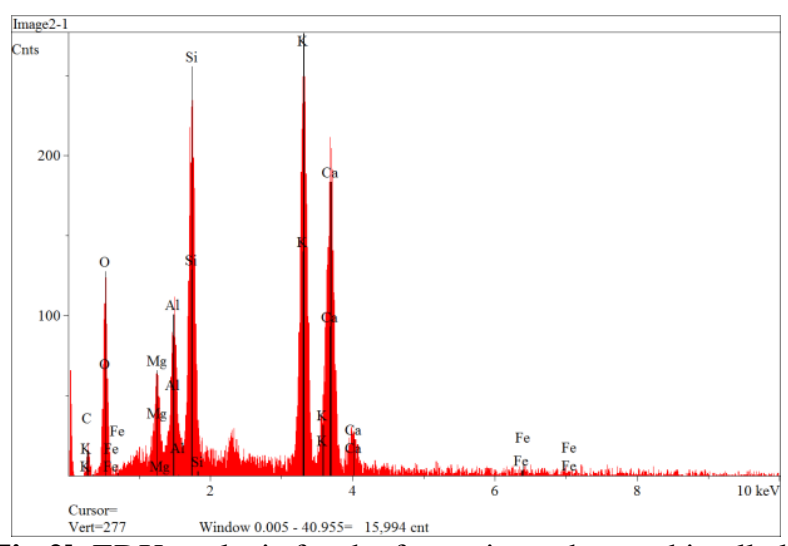

Fig 2b EDX analysis for the formations observed in alkali activated slag.

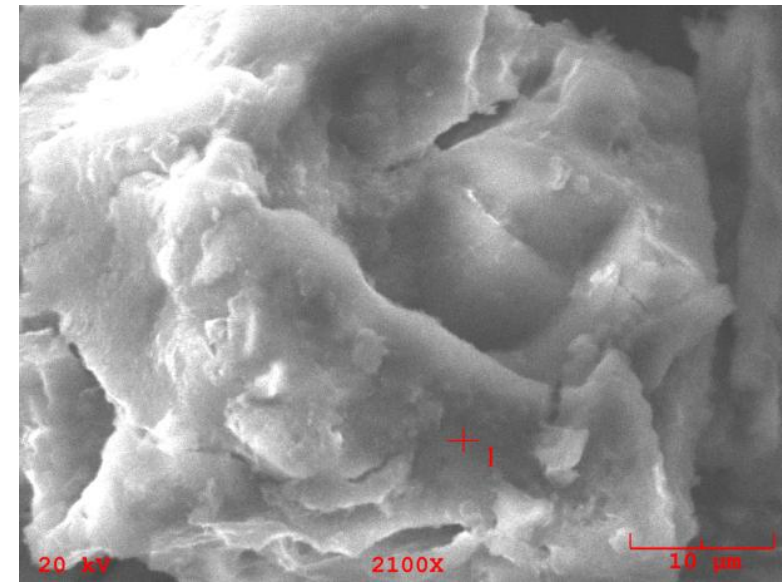

Fig 2c SEM micrographs analysis for the formations observed in alkali activated slag.

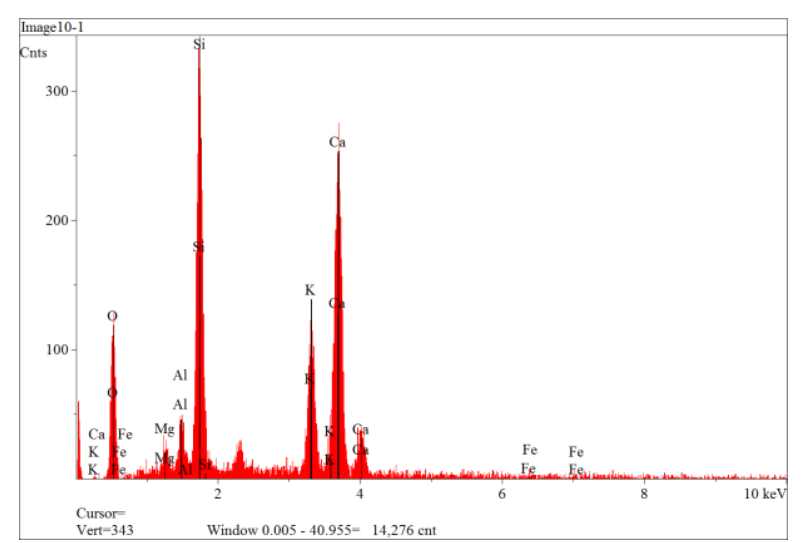

Fig 2d: EDX analysis for the formations observed in alkali activated slag.

In previous experiments, temperatures inside the samples were reaching above $100^{\circ} \mathrm{C}$ when cured at $85^{\circ} \mathrm{C}$, which could have been causing water evaporation and visible cracking. Conclusions suggested keeping the curing temperature between room temperature and $60^{\circ} \mathrm{C}$. All samples in this design of experiments were cured at $45^{\circ} \mathrm{C}$. Figure3shows results from the thermochronibuttons imbedded in a liter of paste (2 parts mining tails, $20 \%$ NYAD G) over a 24 hour period of time. The highest temperature occurs at about 300 minutes and reaches about $60^{\circ} \mathrm{C}$.

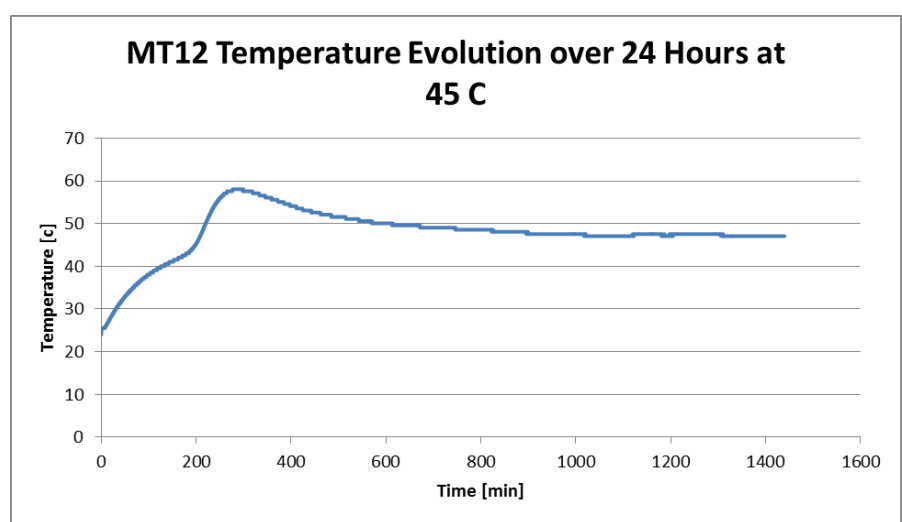

Fig 3.ibutton test for sample MT12, 2 parts per mass, 20\% NYAD G 
Mining tails were used in the experiment as aggregates in order to reduce the cost of the combination, while maintaining the high compressive strength. In order to test the setting time, aVicat needle was used. The initial penetration was $25 \mathrm{~mm}$; it was tested every minute until the needle could not penetrate the sample. Figure 4 shows how the percent of Wollastonite added to the slag affects the samples with 4 parts of mining tails per GGBFS. MT9, MT11, and MT13 contain 20\%, 10\% and $0 \%$ of Wollastonite. The trend display in the figure demonstrates that the Wollastonite acts as a curing accelerator.

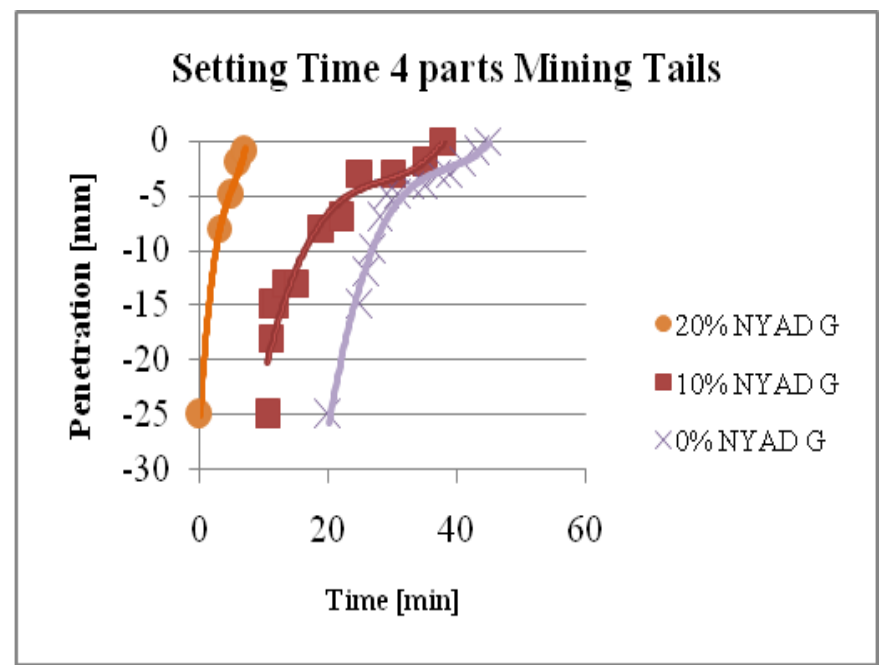

Fig 4 Setting time for samples containing 4 parts mas of mining tails per GGBFS.

In order for an alkali activated material to function as a viable replacement for Portland cement it is required to have a reasonably long curing time. Unfortunately, the combination with $20 \%$ Wollastonite and 4 parts of mining tails was completely cured in less than 10 minutes.

Due to the short setting times displayed in Figure 4, the setting times for samples with 2 parts mining tails were analyzed and are displayed in Figure 5.

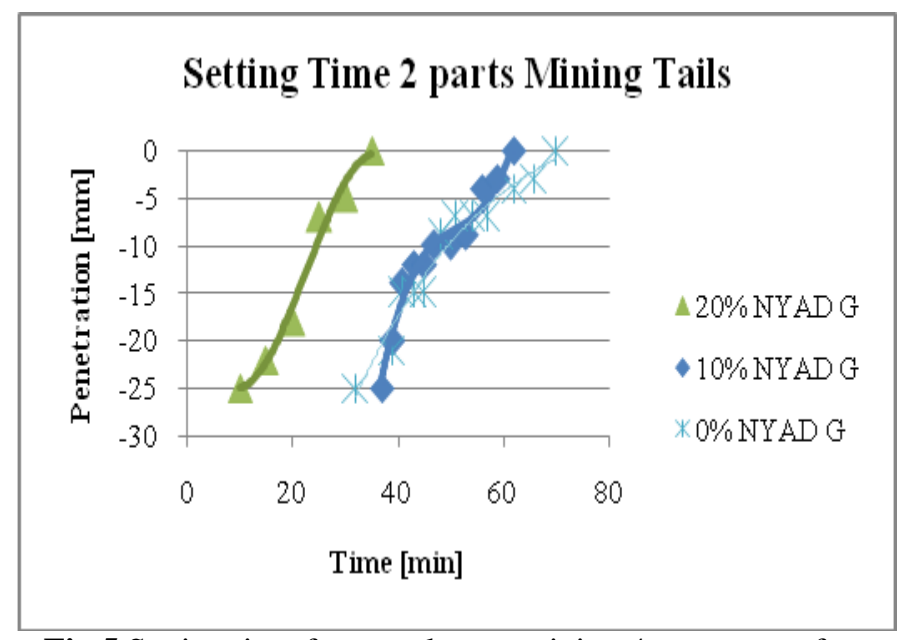

Fig 5 Setting time for samples containing 4 parts mas of mining tails per GGBFS.
Figure 5 now shows how the percent of Wollastonite added to the slag affects the samples with 2 parts of mining tails per part of GGBFS. MT12, MT10, and MT19 contain 20\%, $10 \%$ and $0 \%$ of wollastonite, respectively. The setting time for MT12 is approximately 30 minutes, making this combination a more viable solution for future applications at a greater scale.

\section{DESIGN OF EXPERIMENTS}

The design of experiments consisted on a full, two factorial experiment with three treatment levels, $3^{2}$. The factors studied were the parts of mining tailsper mass of slag, and the percentage of Wollastonite (NYAD G)added to the slag. Table3 displays the levels used for each factor.

Table3: Factors with low, center and high levels used in the design of experiments

\begin{tabular}{|l|l|l|l|}
\hline Factor & $\begin{array}{l}\text { Low } \\
\text { Level }\end{array}$ & $\begin{array}{l}\text { Center } \\
\text { Level }\end{array}$ & $\begin{array}{l}\text { High } \\
\text { Level }\end{array}$ \\
\hline $\begin{array}{l}\text { Mining Tails } \\
\text { (parts per } \\
\text { mass) }\end{array}$ & 0 & 2 & \\
\hline$\%$ NYAD G & 0 & 10 & 4 \\
\hline
\end{tabular}

Each possible combination was mixed, cast and cured accordingly to the process previously discussed. Three samples from each combination were separate and tested the compressive strength after 1,7 , and 15 days of curing. It is a known fact that the compressive strength of the samples is affected by the curing day. However, this factor is out of the scope of the experiment so the data was analyzed separately from each day. Due to the fact that the entire batch combination of samples was created on the same day and with the same conditions. Each set of samples, tested on the different days, is considered to be the same sample tested on different times instead of repetitions. The three levels of each quantitative factor allowed each main effect to be partitioned into linear and quadratic components, containing only one degree of freedom each. The two way interaction were separated into linear * linear, linear* quadratic, quadratic*linear, and quadratic * quadratic.

\section{RESULTS AND DISCUSSION}

For this design of experiments, we used an alpha value of 0.05 in order to have a confidence interval of $95 \%$. The null hypothesis is that there is no effect on the compressive strength caused by the studied factors. The software used in order to analyze the data was Minitab 16 Statistical Software. The lack of repetition caused the degrees of freedom for the error factor to be 0 . Therefore, it was impossible to calculate the $\mathrm{F}$ value for each difference source as it can be seen in Table 4 . 
Table4: ANOVA for Average Day 1

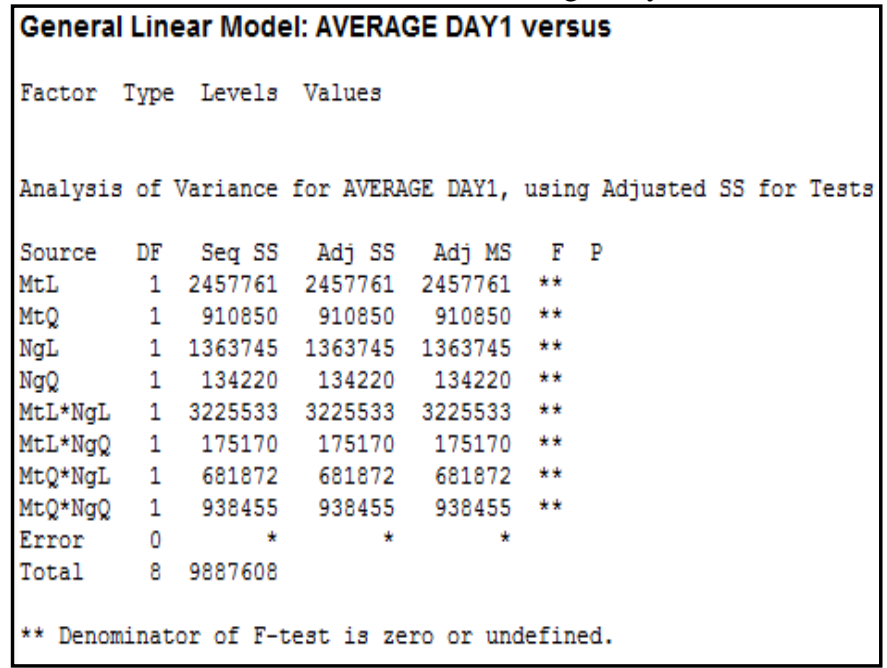

The ANOVA table was created using a regression analysis. There is no available $\mathrm{F}$ value so these results cannot be tested with an $\mathrm{F}$ test to find significance of the factors. However, using the sum of squares, SS, it is seen that both linear main effects and the linear interaction seems to be significant, their SS is greater than the other sources.

The interaction plot, Figure 6, can help us to visually see the effect of the mining tails while changing the mass percentage of NYAD G. When there is no NYAD G, the mining tails have a significant effect on the compressive strength. It increases from approximately $24.13 \mathrm{MPa}$ (3500 psi)up to $44.81 \mathrm{MPa}(6500 \mathrm{psi})$ when 4 parts of mine tailings were used. When the percentage of NYAD G increases, the effect of mining tails decreases.

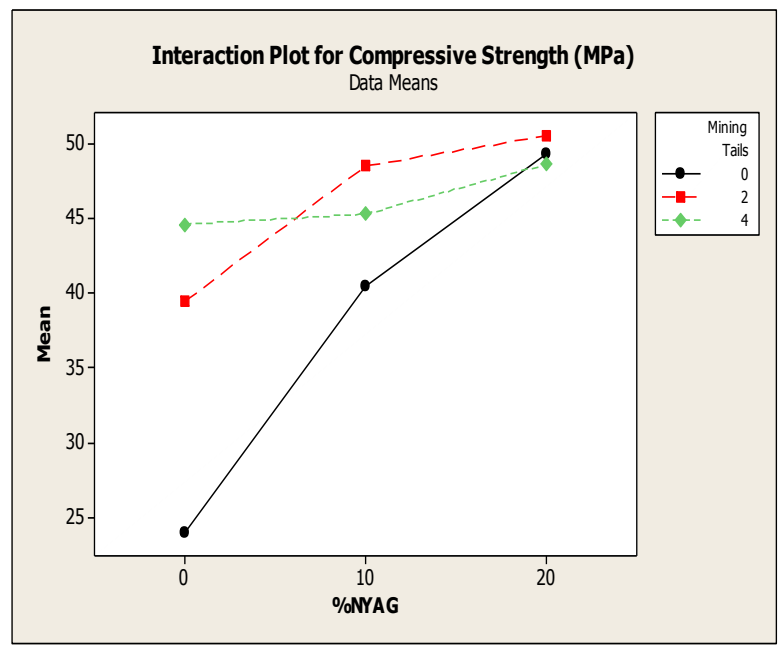

Fig6. Interaction plot for compressive strength

After reviewing this interaction plot, it was found that the at the presence of Wollastonite, the effect of the mining tails decrease. Therefore, another regression analysis was created but running to different sources of mining tails. The ANOVA table for this analysis can be seen in Table 5.
Table 5: ANOVA table for Average Day 1, separating Mining tails.

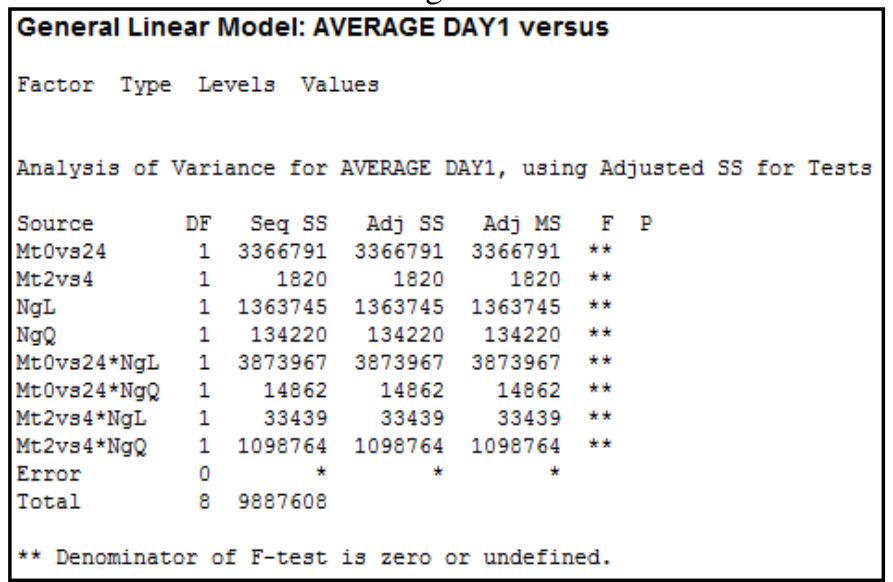

With the use of orthogonal contrasts the effect of the mining tails was separated. MT0vs24 separates the low level from the center and high level. MT2vs4 separates all the levels for the analysis. It can be seen that the source that separates the low level against the other two levels has more significance to the model so it was decided to use Mt0vs24, percent of Wollastonite NYAD G (linear) and its interaction for an analysis of variance. The other sources were not taken into consideration separately on the analysis, and formed part of the error making it possible to perform an $\mathrm{F}$ and $\mathrm{P}$ value test that can be seen in Table 6 .

Table 6: ANOVA and Regression Analysis for the Average Day 1

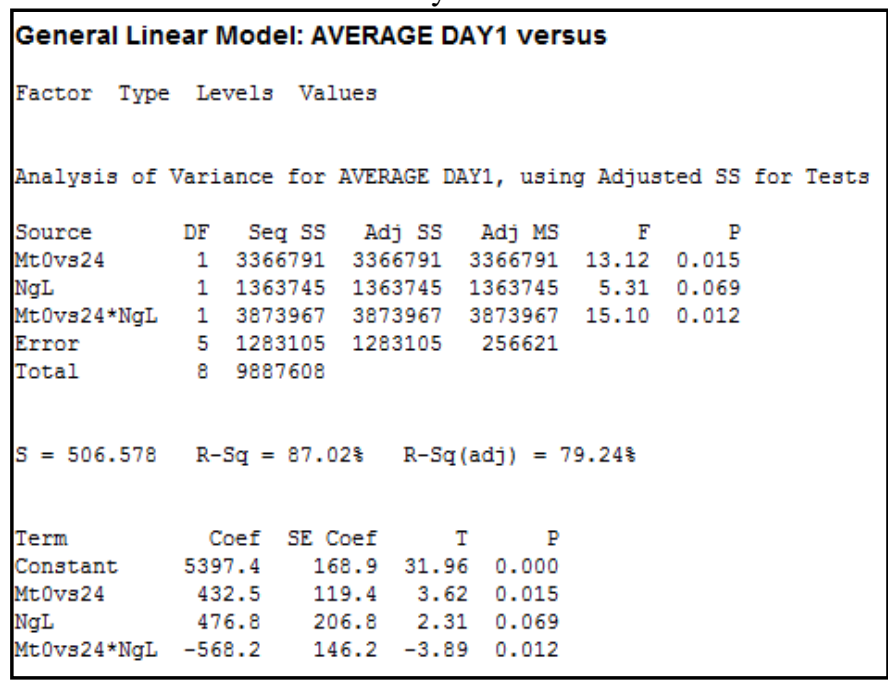

The ANOVA table gives a $\mathrm{P}$ value for each factor studied, by comparing this value to an alpha of 0.05 it can be seen that the main effect of mining tails and its interaction with the percentage of NYAD G has a significant effect on the compressive strength. The main effect of the percent of Wollastonite NYAD G is close to the alpha value so it could be significant. However, more information is needed to confirm its significance. The R-square value, is 87.02 percent, showing that a high percent of the data points fit on the line of the model. The same analysis was followed for 
the data recollected after 15 days of curing. The results can be seen in Table 7

Table 8: ANOVA and Regression Analysis for the Average Day 15

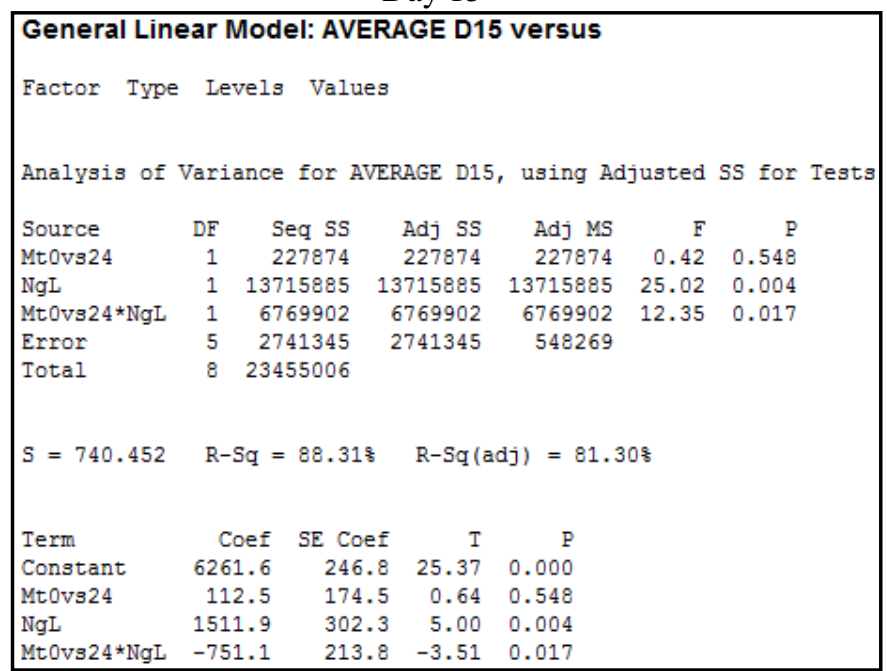

The $\mathrm{P}$ value for the mining tails is greater than the alpha, meaning that this factor is not statistically significant after 15 days of curing. However, the effect of the Wollastonite now seems to be greatly significant as well as their interaction. The results from the analysis of variances demonstrate that with time the effect of the NYAD $G$ on compressive strength increases while the effect of mining tail decreases. The R-square value after 15 days is $88.31 \%$ helping the validity of the regression model.

\subsection{Cost Analysis}

A cost analysis of every different combination was made in order to see the effect of the changes. Table8displays the different contents of mining tails and Wollastonite together with the approximate price per cubic meter.

Table8: Price per cubic meter in US dollars for each combination (containing the mining tails per par mass of slag and percentage of NYAD G)

\begin{tabular}{|l|lr|l|l|}
\hline & $\begin{array}{l}\text { Mining Tails } \\
\text { (parts per } \\
\text { ID }\end{array}$ & $\begin{array}{r}\% \text { NYAD } \\
\text { G }\end{array}$ & Price/m ${ }^{3}$ \\
\hline MT21 & 0 & 0 & 134.4 \\
\hline MT19 & 2 & 0 & 94.1 \\
\hline MT13 & 4 & 0 & 86.7 \\
\hline MT20 & 0 & 10 & 202.4 \\
\hline MT10 & 2 & 10 & 137.5 \\
\hline MT11 & 4 & 10 & 122.7 \\
\hline MT14 & 0 & 20 & 262.4 \\
\hline MT12 & 2 & 20 & 177.6 \\
\hline MT09 & 4 & 20 & 156.7 \\
\hline
\end{tabular}

In order to have a visible representation of how the cost per cubic meter is affected by the different factors, the values were graphed and are shown in Figure 7.

\section{Price per Cubic Meter US \$}

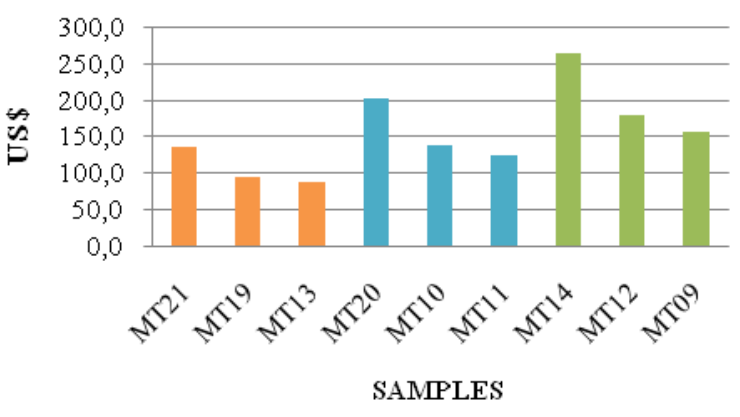

Figure7. Price per cubic meter in US dollars for the different combinations

The samples on the left (MT 21, MT19, MT13) do not contain a percentage of Wollastonite NYADG added to the slag. However, their compressive strength is significantly lower that the samples containing 10\% NYAD G (MT20, MT10 MT11) and 20\% of NYAD G (MT14, MT12, MT09). The trend displayed in Figure 9 shows how the cost per ton is reduced by adding mining tails; samples MT13, MT11 and MT09, which have the lowest cost per cubic meter in each Wollastonite bracket, contain 4 partsof mining tails per mass of slag.

\section{CONCLUSIONS}

This work demonstrates that both factors, parts of mining tails and mass percentage of Wollastonite, have a significant effect on the compressive strength. For samples with $0 \%$ Wollastonite, mining tails are the dominant factor in the compressive strength, and when the mass percentage of wollastoniteincreases, the effect of mining tails is not that significant.

The use of mining tails as an inexpensive aggregate in alkali activated slag has a great effect on the price of the product while maintaining a compressive strength that could be useful as a replacement for Portland cement. The average price for a $34.5 \mathrm{MPa}$ (5000 psi) compressive strength concrete in Western New York is \$138 US. The estimated average price of alkali activated slag was $\$ 900$ US with no aggregates. By adding mining tails, this cost was brought down to the $\$ 96.70$ to $\$ 262.4$ US range, making a more cost efficient alternative.

In these experiments, the combination that displayed the highest mean compressive strength was MT 12, approximately $48.26 \mathrm{MPa}$ (7,000 psi) after 15 days. This was found to be optimal combination was found to be MT12; this combination has setting time of approximately 35 minutes and a price of $\$ 177.6$ per cubic meter. Its highest internal temperature during curing is below $60^{\circ} \mathrm{C}$, lower than $100^{\circ} \mathrm{C}$, this helps to reduce visible cracking by avoiding water evaporation. The future steps for this research will consist on performing durability testing of this combination, weathering for 1 year in Rochester, NY, together with thermal cycling. In order to find the environmental impact of 
this product and compare it to a Portland cement with a compressive strength of 50Mpa a Life Cycle Assessment will be perform using the software SimaPro.

\section{REFERENCES}

[1]. Van Oss, H.G. “Cement." U.S. Geological Survey, Mineral Commodity Summaries, January 2013. n.d. Web. 02 Feb. 2014. <http://minerals.usgs.gov/minerals/pubs/commodity/cement/ mcs-2013-cemen.pdf $>$

[2]. " $\mathrm{CO}_{2}$ Emissions From Cement Production." BuildingGreen.com.N.p., n.d. Web. 21 Oct. 2013. <http://www.buildinggreen.com/features/flyash/appendixa.c fm?IMAGENAME=images/1401/Insul_tabel.gif\&FILENA $\mathrm{ME}=140101 \mathrm{a} . \mathrm{xml}>$

[3]. "The Cement Sustainability Initiative, Cement Industry Energy and $\mathrm{CO}_{2}$ Performance." World Business Council for Sustainable Development.N.P. n.d. Web. 18 Mar. 2014. <http://www.wbcsdcement.org/pdf/CSI\%20GNR\%20Report $\% 20$ final\%2018\%206\%2009.pdf>

[4]. Davidovits, J. "Geopolymers Chemistry \& Applications" InstitutGeopolymére. 2008

[5]. Provis, J.L.,van Deventer, J.S.J.“Alkali Activated Materials.” RILEM State-of-the-Art Reports, Vol. 13, 2014, XIV, 388p.

[6]. Purdon, A. O., "The Action of Alkalis on Blast Furnace Slag" Journal of the Society of Chemical Industry, 59, 1940

[7]. Shi, C., Krivenko P.V.,\& Roy D.(2006). AlkaliActivated Cements and Concretes. Taylor \& Francis

[8]. Fernandez- Jimenez, A., Palomo, J.G., Puertas, F. "Alkali-Activated Slag Mortars Mechanical StrenthBehaviour". Cement and Concrete Research, 29, 1999

[9]. Gonzalez, V., B. Varela, J. Voelkel. "Factors Affecting the Setting Time and Compressive Strength of Alkali Activated Ground Granulated Blast Furnace Slag Reinforced with Wollastonite." International Journal of Innovative Technology and Exploring Engineering 3.10 (2014):

\section{BIOGRAPHIES}

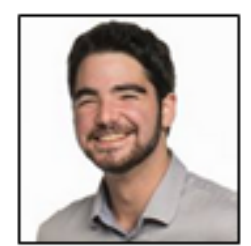

Pablo SantizoMatheu is a $5^{\text {th }}$ year dual degree student with BS in Industrial and Systems Engineering and $\mathrm{MS}$ in Sustainable Engineering. He has been working on alkali activated materials since September 2013

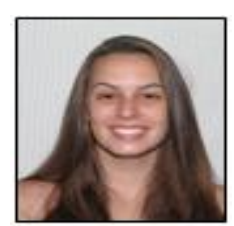

Ashley M. Waldron is a $5^{\text {th }}$ year Mechanical Engineering student at Rochester Institute of Technology in NY. She has been working withalkali activated materials since the summer of 2013 using various forms of wollastonite to improve mechanical properties and reduce cost.

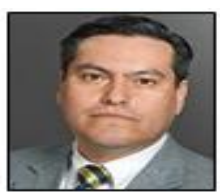

Benjamin Varela isan Associate Professor in the Mechanical Engineering Department at the Rochester Institute of Technology, NY 